\title{
Acoustic Emission from Microcrack Initiation in Polymer Matrix Composites in Short Beam Shear Test
}

\author{
Ireneusz J. Baran ${ }^{1} \cdot$ Marek B. Nowak $^{1}$ • Jan P. Chłopek ${ }^{2} \cdot$ Krzysztof J. Konsztowicz $^{3}$ (D)
}

Received: 13 August 2017 / Accepted: 14 November 2017 / Published online: 16 January 2018

(c) The Author(s) 2018. This article is an open access publication

\begin{abstract}
Acoustic emission (AE) was applied for detection of microcrack initiation in carbon fiber reinforced polymer composites subjected to shear stresses. Experimental materials were prepared from polyester bonded unidirectional (1D) non-crimp fabric and 2D plain-weave carbon fiber fabrics, using the resin transfer moulding technology. Control of epoxy resin/carbon textile proportions enabled variation of fiber volume content from small (34/35\% for 2D/1D), through medium (51\%) to high (68\%). Rectangular samples $(45 \times 4 \times 2 \mathrm{~mm})$ were cut from 1D plates along [0] and across [90] fibers. Similar size samples from 2D plates were cut along warp/weft axes as well as in two orthogonal bias directions. Selected side surfaces were polished for microscopic (SEM) observations. Short-beam-strength tests were performed in 3-point bending $(1 / \mathrm{h}=4)$, with two AE sensors attached for damage monitoring, which allowed to interrupt loading sequence before final failure. The acoustic emission historic index was the most effective AE parameter in damage initiation control. Microcracks developing on polished composite side-surfaces were observed under the SEM and direct microscopic evidence confirmed fiber debonding to be the principal mechanism of crack initiation in these materials and testing conditions before any further damage.
\end{abstract}

Keywords Acoustic emission $\cdot$ CFRP $\cdot$ SBS $\cdot$ Microcrack-initiation $\cdot$ Debonding $\cdot$ Matrix-cracks

\section{Introduction}

Acoustic emission (AE) is considered the most sensitive "real time" technique among all nondestructive evaluation (NDE) methods [1]. Its broader use in composite materials' structural health monitoring (SHM) is still limited by both the complicated nature of equipment [2], and by the transient nature of acoustic emission signal as well as its interaction with internal structure of composite material [3]. Significant progress has been achieved in earlier studies focusing on single AE parametric descriptors (amplitude, duration, counts, energy, rise time), however, the results were not always conclusive regarding the nature of damage initiation stage [4].

Krzysztof J. Konsztowicz

kkonsztowicz@ath.bielsko.pl

1 Institute of Production Engineers, Cracow University of Technology, 31-864 Kraków, Poland

2 Faculty of Materials Science and Ceramics, AGH University of Science and Technology, 30-065 Kraków, Poland

3 Institute of Civil Engineers, University of Bielsko-Biala, 43-309 Bielsko-Biała, Poland
In order to approach these mechanisms in micro-scale [5], more sophisticated analytical methods have been developed, allowing for clustering of AE signals and their pattern recognition [6]. Many authors use wavelet transform for more detailed damage identification and localization [7]. Due to time/frequency uncertainty [3] precise definition of the time of occurrence of specific damage process described by acoustic emission is difficult. It is determined analytically, by „attributing" the AE features to particular damage mechanism like matrix cracking, fiber breakage, debonding, pull-out and delamination, often all examined in one study on a few samples, sometime with complex fiber lay-up. This is not always supported by a convincing experimental evidence $[8,9]$, and the need still exists for a synthetic and reliable indicator of damage onset in fiber composites.

A valuable contribution to experimental determination of the time of failure onset may be derived from the AE Felicity Effect studies, the most successful so far application of acoustic emission to damage studies in composite pressure vessels $[10,11]$. Felicity Effect may be also examined in bending and in shear using step-loading procedure, with continuous monitoring by acoustic emission [12]. In this methodology, an $\mathrm{AE}$ parameter named historic index (HI) is used to establish 
the onset of significant emission. The HI indicates change in "measured area of rectified signal envelope" (MARSE) or another measure of the area of "voltage-time" signal, like AE Energy. It is given [12] by the formula (1):

$$
\mathrm{H}(\mathrm{t})=\frac{\mathrm{N}}{\mathrm{N}-\mathrm{K}} \frac{\sum_{\mathrm{i}=\mathrm{K}+1}^{\mathrm{i}=\mathrm{N}} S_{\mathrm{Oi}}}{\sum_{\mathrm{i}=1}^{\mathrm{i}=\mathrm{N}} \mathrm{S}_{\mathrm{Oi}}}
$$

where $H(t)$ is the historic index at time $t, N$ is the number of AE hits to (and including) time t, $S_{O i}$ is the MARSE value of the ith AE hit, $K$ is empirically derived factor depending on the number of AE hits (given in AE standards).

Historic index is sensitive in detecting variations of slope of cumulative MARSE vs time curve and its changes can be measured in function of time, therefore, it is particularly valuable in determining the onset of damage mechanisms, independently of specimen size and shape. The historic index is analyzed continuously by AE manufacturer's software and depends on a number of AE hits on a channel, usually it is set to unity when the channel has fewer than 100 hits. The onset of significant acoustic emission is defined [12] as the stress level where the value of historic index (HI) becomes equal or greater than 1.4, and this moment of time is indicative of the onset of failure in the examined material. In some experimental studies where higher loading speeds are applied ( $>1 \mathrm{~mm} / \mathrm{min}$ ), the damage initiation timing might be difficult to recognize at sufficiently discreet level. Catastrophic failure progresses quickly, and $\mathrm{HI}$ values (if determined) would be immediately in the range of dozens (e.g. 20 even up to 90), resulting in appearance of larger cracks often observed visually or using NDE methods less sensitive than AE, like $\mathrm{X}$-rays or C-scan [13].

In many practical applications parts made of composite materials are subjected to bending forces, where shear stresses may contribute to damage initiation [14]. Debonding mechanism of damage initiation resulting from shear is gaining increasing attention in recent years, including analytical approaches [15]. A specific case of examination in bending is the short-beam-strength (SBS) test, where specimen's deformation is largely reduced due to the ratio of span-to-thickness equal to 5 or less, and where the shear damage may dominate the failure process $[16,17]$. Several studies have shown that this test is very sensitive to the quality of fiber/matrix interface $[18,19]$ and may be used as estimate of inter-laminar shear strength (ILSS) due to ease of application [17].

The aim of the present work was to observe directly the onset of microcrack initiation in carbon fiber reinforced polymer (CFRP) laminates of basic fiber architectures (unidirectional and plain-weave), subjected to shear stresses during the short-beam-strength (SBS) test. Microcrack initiation control was based on continuous AE monitoring of damage growth with time of test, particularly exploiting the sensitivity of AE historic index (HI) in indication of the onset of new damage mechanisms. The present authors examined earlier [20] these CFRP materials using step-load procedure in 4point bending and after comparing with results of monotonic tests found that $\mathrm{HI}$ values obtained from the latter are equally indicative of damage initiation.

\section{Materials and Methods}

Continuous carbon fiber polymer matrix composites are manufactured by consolidation of fiber laminae, where the orientation of fibers, stacking sequence and the number of fibers across each lamina affect strongly final properties [25]. Due to such complexity the identification of a specific damage initiation mechanism (like matrix cracking) in multidirectional, multilayer laminates is extremely difficult in micro scale, if possible at all using available experimental techniques. In order to reduce the sources of variability, this work concentrated on examination of the two most popular carbon fiber architectures applied in contemporary composites - unidirectional (1D) and plain-weave (2D) laminates. The third series studied were the 2D pseudo angle-ply CFRP materials, and these were of interest because of much larger fracture strains and much lower strengths than in pseudo cross-ply composites [24]. In all three series of composites the effects of fiber volume fraction were evaluated.

\subsection{Sample Preparation}

Carbon fiber/epoxy matrix composite plates of the size $500 \times$ $500 \mathrm{~mm}$ were manufactured with use of resin transfer moulding (RTM) technology, ${ }^{1}$ at resin transfer temperature $60^{\circ} \mathrm{C}$, injection pressure 6 bar and processing time $8 \mathrm{~h}$. The epoxy resin $\mathrm{L}$ was used together with EPH 294 hardener. $^{2}$ The unidirectional (1D) composite RTM plates were made of polyester (PES) bonded Toho Tenax E HTS40 non-crimp fabric (NCF) with carbon fiber strands of $12 \mathrm{~K}$ filaments and linear density 800 tex. Single Toho Tenax HTS40 carbon fibers have average tensile strength of $4300 \mathrm{MPa}$ and tensile modulus $240 \mathrm{GPa}$ [21]. The number of fabric layers and the amount of resin injected during moulding were varied to give final PES bonded 1D products with different fiber volume content (small, medium, large): 35, 51 and 68\%, respectively. The multilayer bidirectional (2D) composites were formed by the same technique from plain-weave fabric ${ }^{3}$ layers made

\footnotetext{
1 By LZS GmbH, Institut fur Leichtbau und Kunstofftechnik, Technische Universitaet Dresden, Germany.

2 both made by R\&G Faserverbundwerkstoffe $\mathrm{GmbH}$ of Waldenbuch, Germany.

3 Manufactured by ECC-C.Cramer GmbH \& Co. KG, Heek, Germany.
} 

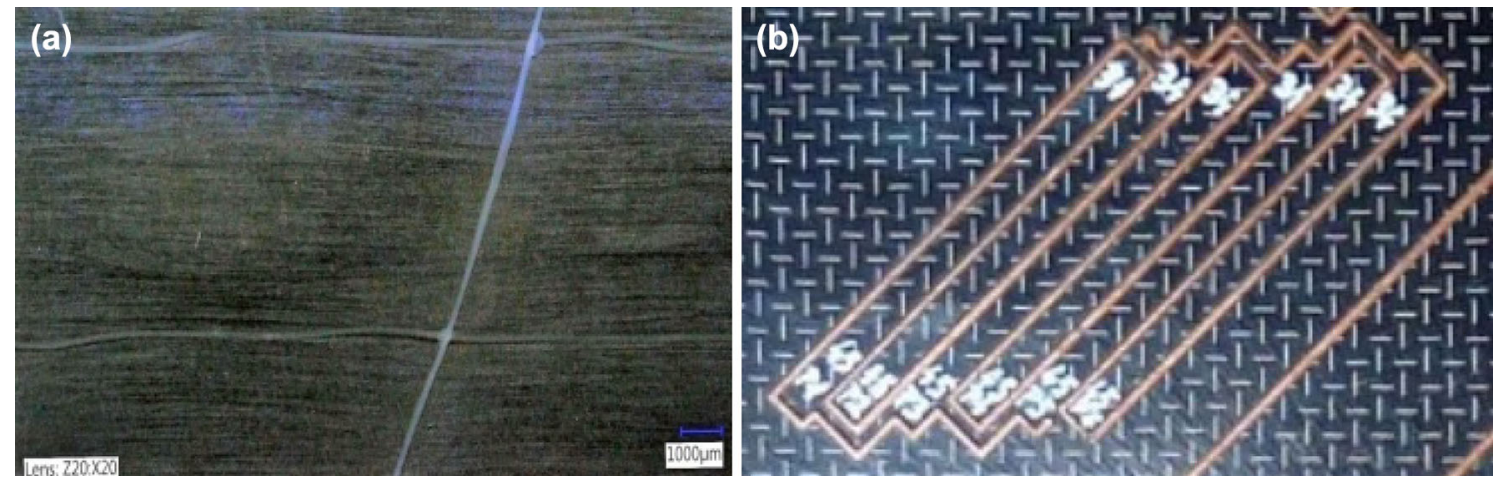

Fig. 1 a Fiber strands on the backside of SBS sample cut from PES bonded 1D CFRP. b The SBS samples cut from plain-weave CFRP composites in one of two bias directions

of the same Toho fibers of linear density 800 tex, with average fabric weight of $600 \mathrm{~g} / \mathrm{m}^{2}$. The volume content of fibers in multilayer 2D plain-weave composite plates was also purposely varied and was determined by the manufacturer as 34 , 51 and $68 \%$, respectively.

Five rectangular composite samples with dimensions $45 \times$ $4 \times 2 \mathrm{~mm}$ were water-jet cut from each of large 1D masterplates in both principal directions, i.e. along [0] and across fibers [90]. Fiber strands lay-up in the examined PES bonded non-crimp fabric (NCF) 1D CFRP is shown in Fig. 1b. In the second series the same size samples were cut from each of 2D plates (each of specific fiber volume content) along warp/fill principal axes of RTM master-plate (designated X,Y), to give fabric lay-up corresponding to cross-ply $[0 / 90]_{\mathrm{n}}$ laminates. In the third series examined similar size samples were cut from 2D plates (with varying fiber volume fractions) in two bias orthogonal directions designated $\mathrm{L}$ and $\mathrm{P}$ (Fig. 1b), corresponding to $[+45]_{n}$ lay-up.

Near 100 short-beam CFRP samples (including necessary repetitions) have been examined in this study with simultaneous registration of acoustic emission data. From about 100 clear SEM micrographs obtained after interrupted mechanical tests and from failed (but not broken) specimens only a few representative micrographs were selected to illustrate this paper, together with corresponding AE data.

\subsection{Mechanical Properties: Short Beam Strength Tests in 3-Point Bending}

The short-beam strength (SBS) tests were carried out in 3point bending (Fig. 2a), with loading span of $8 \mathrm{~mm}(1 / \mathrm{h}=4)$. Tests were performed using mechanical testing machine Zwick Z100, equipped with testXpert v.3.1 software (by Zwick). Loading data were transferred through parametric output of testing machine to input module of the acoustic emission system, allowing for simultaneous registration of force and displacement and correlation with acoustic emission signals obtained from loaded samples. The cross-head

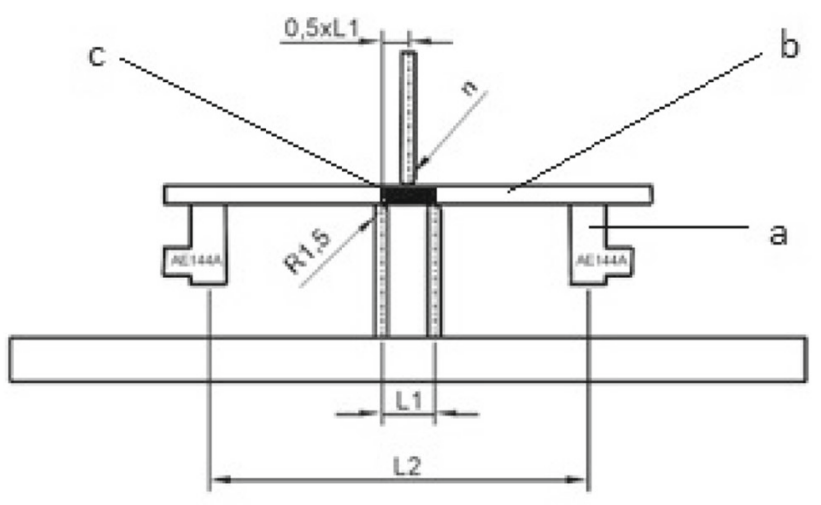

Fig. 2 Experimental set-up for SBS 3-p bending tests: a AE sensors. b CFRP sample placed on bending supports. c SEM observed area of sample side-surface (between bending supports)

speed applied in most cases was $1 \mathrm{~mm} / \mathrm{min}$ and in specific cases of weaker samples it was reduced to $0.25 \mathrm{~mm} / \mathrm{min}$. The same speed of $0.25 \mathrm{~mm} / \mathrm{min}$ was applied during loading of samples with pre-polished side-surfaces (used later for microscopy), while a few very fragile 1D [90]n transverse microscopic samples were loaded at $0.1 \mathrm{~mm} / \mathrm{min}$.

\subsection{Acoustic Emission}

The acoustic emission (AE) signals were registered with use of AMSY6 system ${ }^{4}$ equipped with Vallen software for parametric and transient data acquisition and analysis. Two small size broad-band sensors (Fuji AE144A) were attached to sample's outer surface with rubber band and vacuum grease as a coupling agent, followed by Vallen AEP4 preamplifiers set to $34 \mathrm{~dB}$. The AE signals obtained from these two sensors were registered separately as Chan $=1$ and $\mathrm{Chan}=2$, respectively. The spectrum of Fuji AE144A broad-band sensor covers frequencies from 50 to $700 \mathrm{kHz}$. The acoustic

\footnotetext{
4 Vallen Systeme GmbH, Schaeftlarner Weg 26a 82057 Icking, Germany.
} 

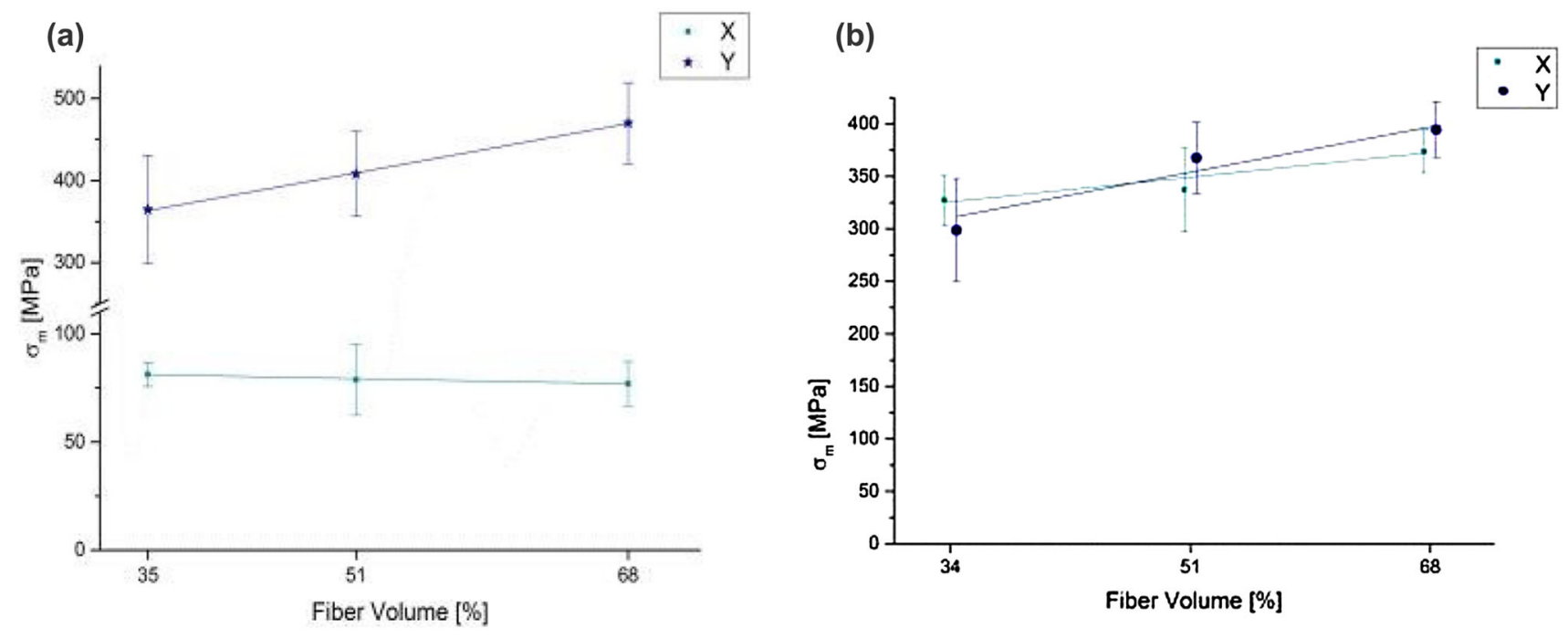

Fig. 3 a The values of 3pb SBS for PES bonded 1D NCF CFRP samples cut in longitudinal (Y) and transverse (X) direction to fibers, in function of varying fiber volume content. b The values of 3pb SBS for plain-weave CFRP samples cut along warp/fill fiber tows (X,Y) increasing with fiber volume content

emission coupling was calibrated before each measurement using the Hsu-Nielsen source in form of $2 \mathrm{H}$ hardness graphite pencil $3 \pm 0.5 \mathrm{~mm}$ long [22]. The following parameters of acoustic emission data acquisition during the SBS bending tests were used: system gain $34 \mathrm{~dB}$, threshold 25 , 3-46 dB (depending on type of sample), duration discrimination time $200 \mu \mathrm{s}$, TR sample rate $5 \mathrm{MHz}, 2048$ samples per TR set. For determination of $\mathrm{AE}$ historic index the AE location control was applied to extract signals originating only between lower supports of 3-point bending set-up (L1 in Fig. 2).

\subsection{SEM Observations}

Two of each set of 5 samples per material/direction had one of their side-surfaces polished for microscopic (SEM) observations. After gaining experience in controlling the evolution of historic index during loading of unpolished samples, the "microscopic” samples were loaded at lower cross-head speed. After significant increase of historic index (near and above 1.4), the loading was interrupted at stress levels much lower than critical, while some samples failed before operator's intervention. Due to slow cross-head speed the fractured samples did not break apart and conserved their initial shape intact, which allowed to observe directly the defects formed at side-surface during the final failure. The microscopic observations were carried out using the high resolution scanning electron microscope Nova NanoSEM $200 .^{5}$ Uncoated samples were observed in secondary electron mode (SE) in low vacuum conditions (60 Pa) and at relatively low voltage $(5 \mathrm{kV})$.

5 FEI Company, Europe NanoPort, Achtseweg Noord 5, 5651 GG Eindhoven, The Netherlands.

\section{Results and Discussion}

\subsection{Short-Beam-Strength (SBS) \& Interlaminar Shear Strength (ILSS)}

As shown in Fig. 3a, the SBS values for 1D non-crimp-fabric (NCF) CFRP measured along fibers (dir. Y) increase proportionally to fiber volume, following the rule of mixtures [14]. The same applies to composites with undulated fiber tows in plain-weave CFRP materials [23], in samples cut in orthogonal directions along fiber tows (Fig. 3b), as well as in samples cut in two orthogonal bias directions. In the latter case, the absolute values of SBS are much lower than those measured for samples cut along warp/fill tows, while their fracture strains are much larger $[24,25]$.

The inter-laminar shear strength (ILSS) of examined composites is represented by the SBS values measured in [90]n transverse direction (denoted X in Fig. 3a) in PES bonded 1D CFRP NCF. These values are not affected by fiber volume, as they depend mostly on fiber/matrix interfacial properties [26]. Gao et al. [27] indicated that ILSS values determined by the SBS tests for a given system are usually some 30\% lower than the interface debond strength determined by single fiber composite (sfc) technique [28]. Considering the simplicity of the SBS test as compared to single fiber composite tests, it seems to be a reasonably good estimate of interfacial properties of the examined material. The average ILSS values $(\sim 75 \mathrm{MPa})$ measured here on the 1D NCF CFRP are of the same order of magnitude as measured by Gao et al. [27] on similar CFRP materials ( $\sim 80 \mathrm{MPa}$ ), while these authors indicated the value of interface debond strength of the order of $105 \mathrm{MPa}$. 

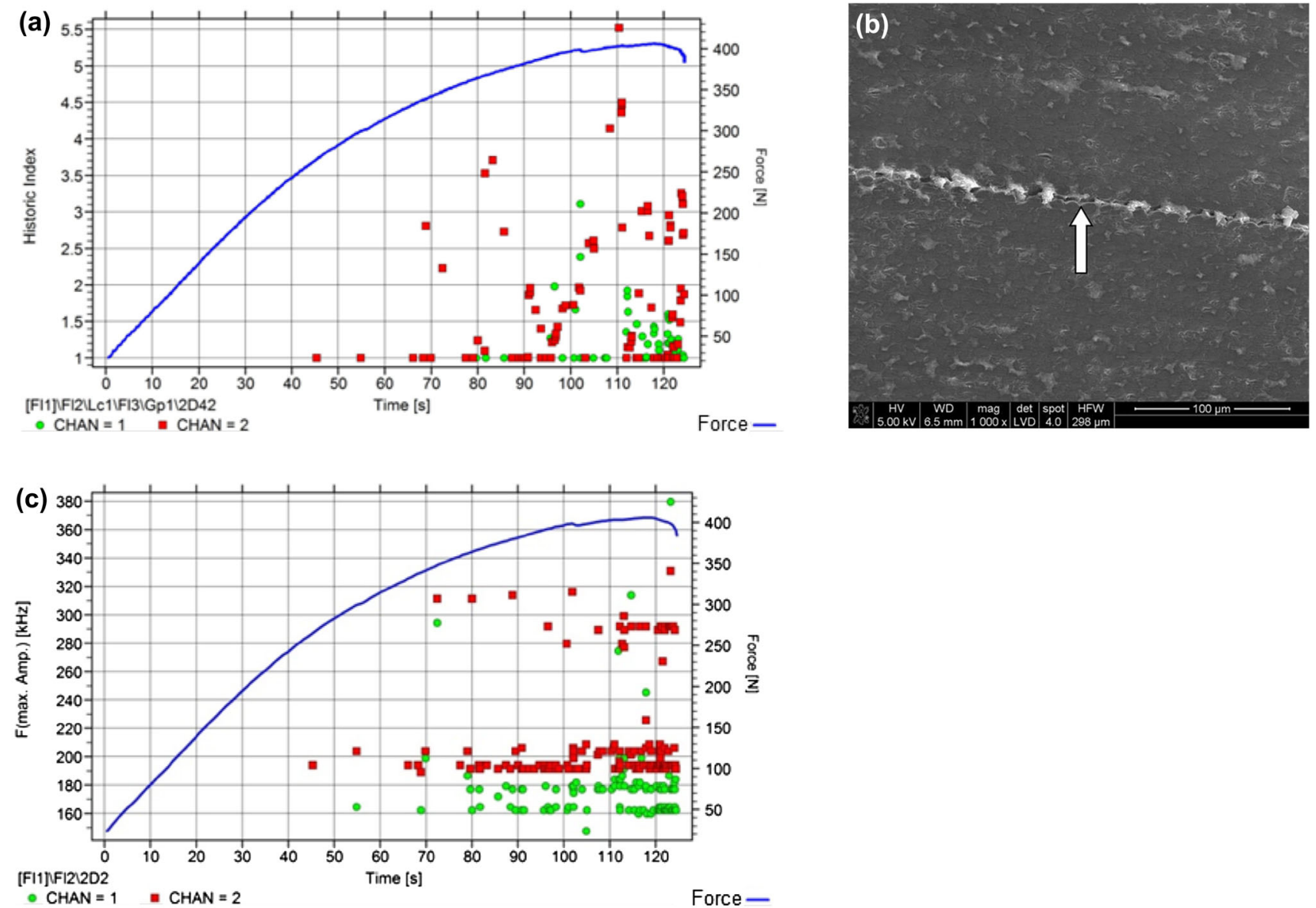

Fig. 4 a The increases of AE historic index registered by both AE sensors (Chan 1, Chan 2) versus load versus time of interrupted SBS test in CFRP sample cut in bias direction (pseudo-angle ply). b Coalescence of individual debonds into longitudinal crack along larger axis of fiber tow, observed in SEM on side-surface of CFRP pseudo-angle ply mate-

\subsection{Acoustic Emission and Microscopic (SEM) Analyses}

Due to short source to sensor distance and its small ratio to sample thickness (Fig. 2), there was no attempt in this work to analyze the propagation properties of acoustic emission $(\mathrm{AE})$ waves $[1,3]$ in examined materials. The registered AE parametric descriptors did not reveal any specific correlation patterns, neither in relation to carbon fiber lay-up and/or volume fraction, nor to damage mechanisms observed in composites [1]. This is to no surprise, seen the examples available in bibliography, reporting different values of $\mathrm{AE}$ parameters obtained by different authors, as cited by $\mathrm{Li} \mathrm{Li}$ et al. [29,30] and Gutkin et al. [31]. The observed here AE cumulative hit numbers varied irregularly in wide range of values, from 15 in some bias and 1D samples to 1500 in pseudo cross-ply plain-weave composites. The plots of AE energy increase in function of time not always had typical rial after interrupted 3pb SBS test. $\mathbf{c}$ The AE frequencies for maximum amplitude (FmA) registered by both AE sensors versus time of SBS test interrupted in CFRP sample cut in bias direction, together with load vs time curve

"2 knee" shape [5,32] facilitating damage growth analysis. They were of both convex and concave shape, and in some cases of interrupted as well as fractured samples they showed only sudden energy increase near the end of test.

Highest amplitudes (75-100 dB) reported in bibliography as related to fiber breakage $[1,30]$, were not observed in any of the materials examined in SBS conditions. Fiber breaks were not found on the analyzed side-surfaces of CFRP samples, other than incidental longitudinal splits sometime observed in central shear plane. The AE amplitudes were generally not higher than $75 \mathrm{~dB}$, most often falling in the average range of 40-65 dB, and showing significant number of signals of amplitudes below $45 \mathrm{~dB}$. In majority of cases the rise time of AE signals showed natural tendency to form clusters around values of 1 (or less), 3, 5 and $10 \mu \mathrm{s}$.

The frequency spectra of acoustic emission signals were obtained in this work using the Fast Fourier Transform (FFT) software provided by Vallen Systeme GmbH. The 

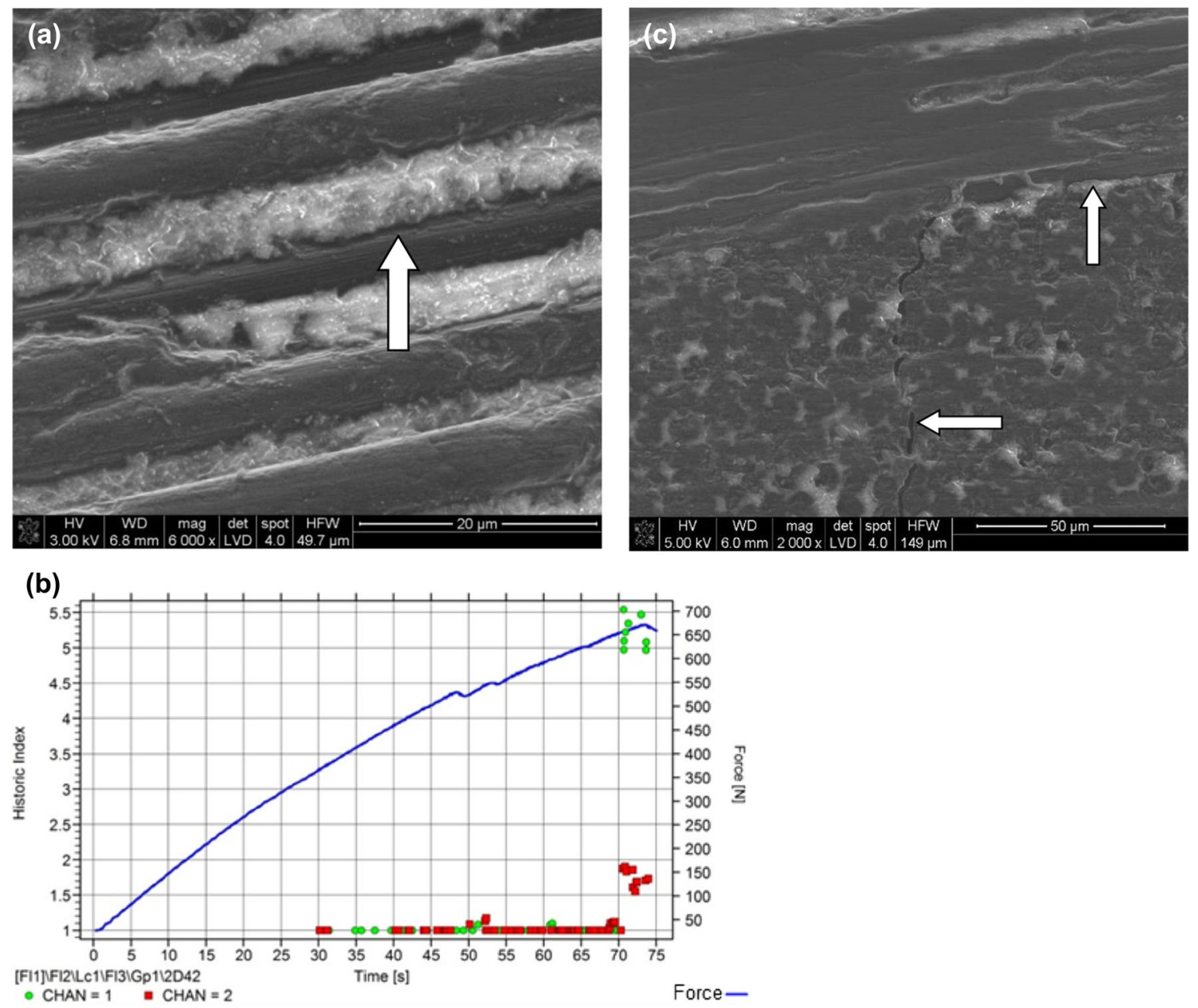

Fig. 5 a Fiber debond observed after interrupted SBS test of plainweave CFRP sample cut along warp/fill. b The AE historic index registered by both $\mathrm{AE}$ sensors (Chan 1, Chan 2) versus time of SBS

$\mathrm{AE}$ frequencies (for maximum amplitude - FmA) of CFRP materials examined in SBS tests appeared mostly in the range of 180 to $260 \mathrm{kHz}$, indicated in bibliography as characteristic of interphase phenomena, including fiber/matrix debonding $[30,31,33]$. These features were in most cases confirmed here by direct SEM observations. Higher frequencies $(>300 \mathrm{kHz})$, attributed to fiber breakages [30], have been registered only on a few occasions, without confirming SEM micrographs. The physical decohesive phenomena described by $\mathrm{AE}$ frequencies of lower values of around 100 $\mathrm{kHz}$ (from a few dozens to $\sim 180 \mathrm{kHz}$ ), may be related to observed micrometer size matrix microcracking defects. Accurate location of such defects by the acoustic emission techniques is practically impossible $[34,35]$ and reliable experimental evidence of these smallest cracks is not available in bibliography, besides contribution by Lorenzo and Hahn [36].

From all the AE parameters examined in this study, the most valuable from the point of view of identification of tim- test versus load, for fractured plain-weave CFRP sample. c Inter and intra-laminar cracks on side-surface of CFRP sample fractured in SBS test

ing of damage initiation appeared to be the historic index. It showed significant increases in function of time of test, most often long enough before catastrophic failure, in composites with different fiber architecture and fiber volume fractions. Practically in all materials tested the SEM images correlated well with damage initiation denoted by low HI values, between 1,4 and 5. These low HI values prove that in fact the onset of first failure was identified in these CFRP composites in SBS testing conditions.

\subsubsection{Shear Tests in CFRP Samples Cut in Bias Directions (Pseudo Angle-Ply)}

In these materials the shear defects in form of fiber debonding were dominant and they were the most visible in performed SEM analyzes, as the shear stresses in this SBS experimental set up may be reinforced by the fiber "scissoring effect" [24]. In selected CFRP composite samples with average fiber volume content $(51 \%)$, the SBS test was interrupted after 

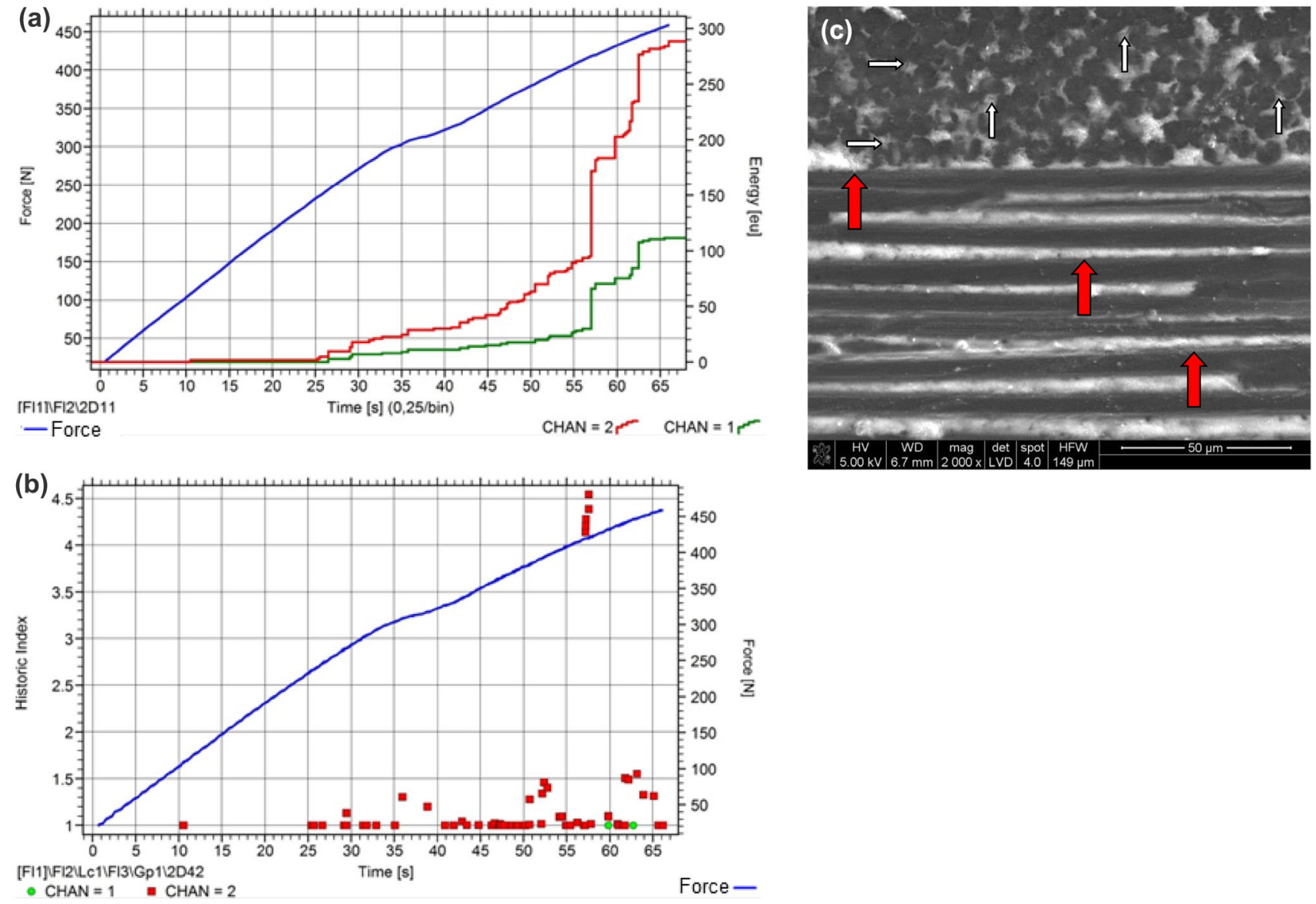

Fig. 6 a Cumulative AE energy versus time of SBS test registered by two AE sensors (Chan 1, Chan 2) attached to plain-weave CFRP sample, shown together with loading curve. b Indications of historic index in function of time of interrupted SBS test for plain-weave CFRP

the AE historic index exceeded the value of 1,4 (Fig. 4a), and their polished side-surfaces were subjected to detailed SEM observations. Fig. 4b shows the coalescence of individual debondings into the line of longitudinal crack along larger axis of fiber tow [37]. The AE frequency for maximum amplitude (FmA) is indicative (Fig. 4c) of interphase area damage ( $\sim 200 \mathrm{kHz})$, and also include some fiber breakages $(>300 \mathrm{kHz})$, the latter feature not confirmed by SEM observations. Interestingly, the $\mathrm{AE}$ signal severity obtained from unbroken CFRP sample in this interrupted test is an order of magnitude larger than in samples failed in test, which is not consistent with similar results known for metals [38].

\subsubsection{Shear Tests in CFRP Samples Cut Orthogonally Along Warp/Fill Directions}

In all samples of this type the increases of AE historic index in function of time of test were always indicative of dam- sample, together with corresponding load vs time curve. $\mathbf{c}$ Damage initiation in sample cut from plain weave CFRP along warp/fill axes. SEM evidence of initiating matrix (narrow arrows) and debonding (wider arrows) microcracks age either initiating in interrupted samples (Fig. 5a), or final damage approaching in samples loaded to failure.

The AE frequency (FmA) data for samples cut along warp/fill axes show dominance of signals of medium range values, related in bibliography to interphase phenomena $[29,31,33]$, and confirmed here by direct SEM observations. The SEM micrographs obtained after interruption of test showed the presence of debonding defects only, appearing either within fiber tows (Fig. 5a) or at the tow/matrix interface. They confirmed the suggestion of an analytical model, indicating that debonding microcracks may appear near fiber discontinuities within the tow [39]. In samples failed but not destroyed in the test, the SEM observations revealed the presence of debonding defects between and inside fiber tows (Fig. 5c).

It was noted that in some cases of plain-weave CFRP composites the AE energy plots differed strongly for two sensors attached to both ends of the same sample (Fig. 6a). The dominant $\mathrm{AE}$ frequencies $(\mathrm{FmA})$ registered by one of 

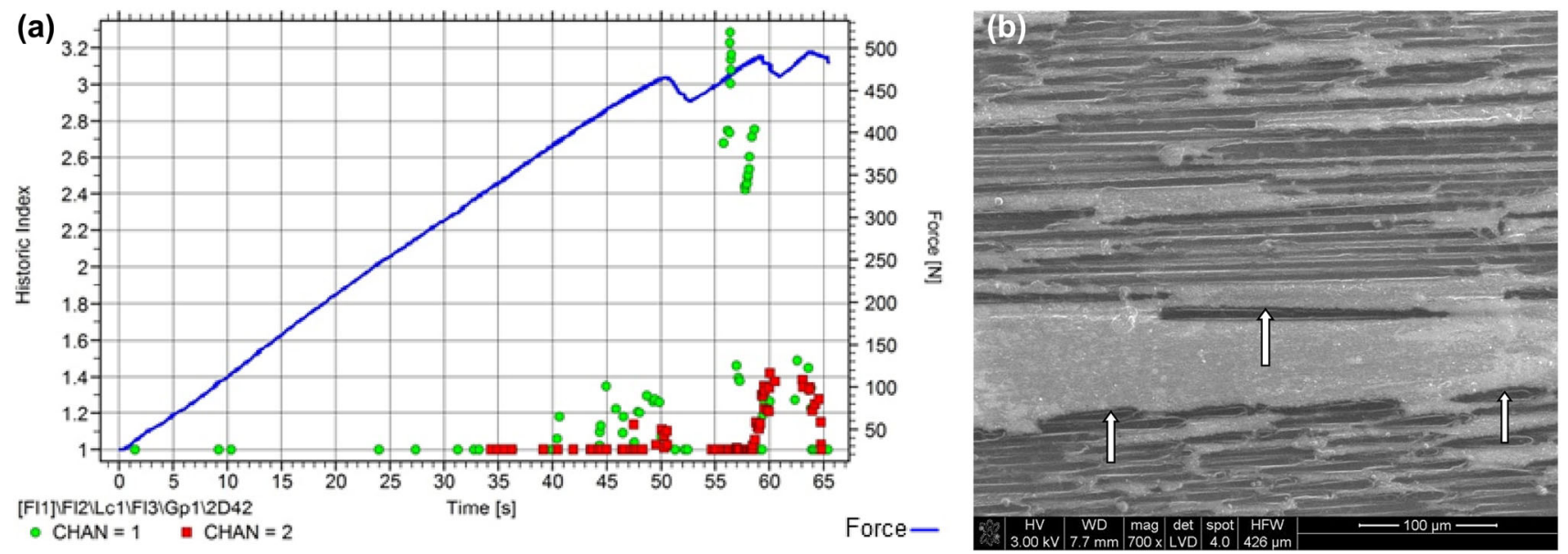

Fig. 7 a The AE HI increases registered by both AE sensors (Chan.1 Chan 2) versus time of interrupted SBS test in 1D PES bonded NCF CFRP sample cut along fibers, shown together with loading curve. $\mathbf{b}$

The SEM evidence for damage initiation (debonding near fiber free ends) in central shear zone of the sample cut along fibers from 1D PES bonded NCF CFRP
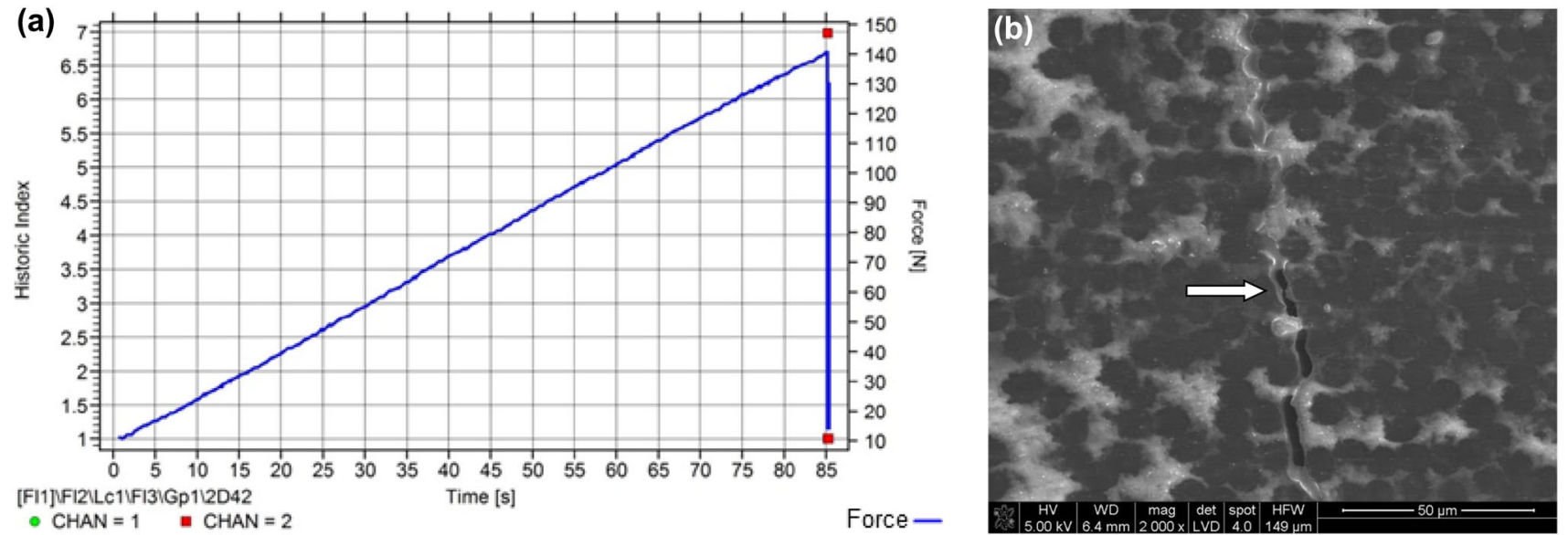

Fig. 8 a The AE HI data registered during SBS test of fractured sample cut transversely to fibers from 1D PES bonded NCF CFRP, versus time of test versus load b The microscopic (SEM) evidence of debonding damage in fractured sample of PES bonded NCF 1D CFRP cut transversely to fibers

sensors oscillate near $160 \mathrm{kHz}$, which is believed characteristic of epoxy resin matrix microcracking in this experimental set-up [40]. After the historic index showed a few distinct increases the loading was interrupted, despite short duration of the test (Fig. 6b). The SEM observations of sample's side-surface (Fig. 6c) revealed the presence of fiber debonds between and inside fiber tows (wider arrows), parallel to shear mid-plane. Some very fine matrix microcracks could be also distinguished in the spaces between fibers in tow vertical to picture plane, near tows' crossing (narrow arrows in Fig. 6b). These are epoxy resin matrix microcracks, the same as originally presented in 1988 by Lorenzo and Hahn $[36,40]$.

\subsubsection{Shear Tests in Samples of 1D NCF CFRP Composites Cut Along and Across Fibers}

The AE and microscopic data for 1D sample cut along fibers (with average volume content of 51\%) are shown in Fig. 7a, b. Loading of this sample was interrupted after the increases of historic index to the values near and above 1,4 (Fig. 7a). The irregularity of final part of loading curve was not correlated with observations of any major defectiveness during the SEM analyses of polished side surfaces. Dominant frequencies $(\mathrm{FmA})$ appeared in rather narrow range of 230 to $260 \mathrm{kHz}$ typical for interphase phenomena, and debonding defects (Fig. 7b) were observed in shear mid-plane near fiber free ends, in agreement with the model proposed by Tang and Whitcomb [39]. 
The failure of PES bonded 1D NCF CFRP composite samples cut transversal to fibers was almost "noiseless" from the AE point of view. The shape of loading curve in Fig. 8a shows fully brittle behavior of this material in the applied loading set-up. No accumulation of AE energy could be observed during loading and all registered AE signals appeared only at the time of final rupture. Specifically in the case samples with transversal fibers (and with instrumental settings used) the historic index did not show variations during the loading process (Fig. 8a), with indications only at final rupture. The sample fractured in SBS test remained macroscopically intact, which enabled the SEM observations of its polished side-surface. This examination (Fig. 8b) revealed the presence of multiple debonding defects forming longer transversal crack, between sample's surface under tensile and the area of central plane under shear stress.

Interestingly, presented here results of debonding under shear correspond closely to results obtained by Lomov and co-workers $[5,24]$ on similar materials subjected to tensile stresses. These authors showed experimental evidence of debonding micro-cracks developing in direction parallel to the acting force, which may also confirm the dominant role of shear stresses in crack initiation process in CFRP composite materials, in general agreement with the model proposed by Quaresimin et al. [15,41].

\section{Conclusions}

- Simple methodology combining the AE monitoring with SEM observations of polished samples' side surfaces allowed to detect the process of microcrack initiation in CFRP composites with different fiber architectures and volume contents in short beam testing set-up.

- Acoustic emission historic index is confirmed to be an excellent indicator of damage initiation in CFRP subjected to short beam shear tests, irrespective of fiber lay-up and volume content. Low HI values (from 1,4 to 5) prove that in fact the onset of first failure was identified in these CFRP composites in SBS conditions. This may be of engineering relevance to structural health monitoring (SHM) of fiber composites, e.g. allowing for early activation of stress reduction mechanisms and/or application of self-healing processes before excessive damage growth. To date there is not enough experimental data and information in bibliography that would enable to correlate systematically the $\mathrm{HI}$ values with damage mode and severity in terms of size of observable cracks.

- Damage initiation in the examined composites subjected to shear stresses in SBS tests is dominated by microscopically confirmed fiber/matrix debonding, which is also in good agreement with indications of AE frequency.
Acknowledgements The authors wish to express their thanks to NCN (National Science Centre, Poland) for financing this work with grant No NCN 2011/03/B/ST5/03180. Authors are also grateful to Dr Magdalena Ziabka of AGH University of Science and Technology, Krakow, Poland, for excellence in use of SEM techniques and to Mr. B. Kotecki (AGH University of Science and Technology, Krakow, Poland), for careful preparation of samples for microscopic observations.

Open Access This article is distributed under the terms of the Creative Commons Attribution 4.0 International License (http://creativecomm ons.org/licenses/by/4.0/), which permits unrestricted use, distribution, and reproduction in any medium, provided you give appropriate credit to the original author(s) and the source, provide a link to the Creative Commons license, and indicate if changes were made.

\section{References}

1. Ono, K., Gallego, A.: Research and Applications of AE on Advanced Composites. In: 30th European Conference on Acoustic Emission Testing \& 7th International Conference on Acoustic Emission, University of Granada, Sept 12-15 (2012)

2. Vallen, H.: AE testing fundamentals, equipment, applications. J. Non Destr. Test. www.ndt.net 7/9 (2002)

3. Carp, S.S.C.S.: Guidance for development of $\mathrm{AE}$ applications on composites. J. Acoust. Emiss. 11, C11-C24 (1993)

4. Dzenis, Y.A., Qian, J.: Analysis of microdamage evolution histories in composites. Int. J. Solids Struct. 38, 1831-1854 (2001). https:// doi.org/10.1016/s0020-7683(00)00138-4

5. Lomov, S.V., Ivanov, D.S., Truong, T.C., et al.: Experimental methodology of study of damage initiation and development in textile composites in uniaxial tensile test. Compos. Sci. Technol. 68, 2340-2349 (2008). https://doi.org/10.1016/j.compscitech. 2007.07.005

6. Sause, M.G.R., Gribov, A., Unwin, A.R., Horn, S.: Pattern recognition approach to identify natural clusters of acoustic emission signals. Pattern Recogn. Lett. 33, 17-23 (2012). https://doi.org/10. 1016/j.patrec.2011.09.018

7. Bianchi, D., Mayrhofer, E., Groeschl, M., Betz, G., Vernes, A.: Wavelet packet transform for detection of single events in acoustic emission signals. Mech. Syst. Signal Process. 64-65, 441-451 (2015). https://doi.org/10.1016/j.ymssp.2015.04.014

8. Pashmforoush, F., Fotouhi, M., Ahmadi, M.: Damage characterization of glass/epoxy composite under three-point bending test using acoustic emission technique. J. Mater. Eng. Perform. 21, 13801390 (2012). https://doi.org/10.1007/s11665-011-0013-2

9. Liu, P.F., Chu, J.K., Liu, Y.L., Zheng, J.Y.: A study on the failure mechanisms of carbon fiber/epoxy composite laminates using acoustic emission. Mater. Des. 37, 228 (2012). https://doi.org/10. 1016/j.matdes.2011.12.015

10. Hamstad, M.A.: A discussion of the basic understanding of the felicity effect in fiber composites. J. Acoust. Emiss. 5, 95-102 (1986)

11. Abraham, A.R.A., Johnson, K.L., Nichols, C.T., Saulsberry, R.L., Waller, J.M.: Use of statistical analysis of acoustic emission data on carbon-epoxy COPV materials-of-construction for enhanced felicity ratio onset determination. NASA Report JSC-CN-26080, pp. $1-15(2012)$

12. ASTM E2478-11 Standard Practice for Determining DamageBased Design Stress for Glass Fiber Reinforced Plastic (GFRP) Materials Using Acoustic Emission. www.astm.org (2011)

13. Ativitavas, N.: Acoustic emission signature analysis of failure mechanisms in fiber reinforced plastic structures. $\mathrm{PhD}$ thesis, University of Texas at Austin (2002) 
14. Kelly, A., Zweben, C.: Comprehensive Composite Materials. Elsevier, Oxford (2001)

15. Carraro, P.A., Quaresimin, M.: Modelling fibre-matrix debonding under biaxial loading. Compos. Part A Appl. Sci. Manuf. 61, 33-42 (2014). https://doi.org/10.1016/j.compositesa.2014.01.016

16. ASTM D2344 / D2344M: Standard Test Method for Short-Beam Strength of Polymer Matrix Composite Materials and Their Laminates. www.astm.org (2013)

17. Chaterjee, S., Adams, D., Oplinger, DW.: Test Methods for Composites a Status Report: Volume III Shear Test Methods. US Department of Transport, Fed Aviation Admin, Rep No DOT/FAA/CT-93/17, III, FAA Technical Center, Atlantic City (1993)

18. Edwards, J.H.: The Use of Acoustic emission to Detect the Onset of Interlaminar Shear Failure in Short Beam Fatigue Specimens. In: Whitcomb, J.D. (ed.) Composite Materials: Testing and Design (Eighth Conference). ASTM STP 972, Philadelphia, pp. 369-379 (1988)

19. Baley, C., Grohens, Y., Busnel, F., Davies, P.: Application of interlaminar tests to marine composites. Relation between glass fibre/polymer interfaces and interlaminar properties of marine composites. Appl. Compos. Mater. 11, 77-98 (2004). https://doi. org/10.1023/b:acma.0000012884.02847.65

20. Nowak, M., Panek, M., Baran, I., Konsztowicz, K.: Acoustic emission detection of damage initiation in plain-weave CFRP loaded in bending. In: Proceedings of ECCM 17, Munich, Germany, 26-30th June, paper 4.03-01 (2016)

21. Toho product specification. http://www.tohotenax.com/products/ tenax/carbon-fiber

22. ASTME 1106 Standard Method for Primary Calibration of Acoustic emission Sensors. www.astm.org (2013)

23. Naik, R.A.: Failure analysis of woven and braided fabric reinforced composites. J. Compos. Mater. 29, 2334-2363 (1995)

24. Bogdanovich, A.E., Karahan, M., Lomov, S.V., Verpoest, I.: Quasistatic tensile behavior and damage of carbon/epoxy composite reinforced with 3D non-crimp orthogonal woven fabric. Mech. Mater. 62, 14-31 (2013). https://doi.org/10.1016/j.mechmat.2013. 03.005

25. Chung, D.D.L.: Processing-structure-property relationships of continuous carbon fiber polymer-matrix composites. Mater. Sci. Eng. R Rep. 113, 1-29 (2017). https://doi.org/10.1016/j.mser. 2017.01.002

26. Kim, ang-Kyo, Mai, Yiu-Wing: Engineered Interfaces in Fibre Reinforced Composites. Elsevier Science, Oxford (1998)

27. Gao, S.L., Mader, E., Zhandarov, S.F.: Carbon fibers and composites with epoxy resins: topography, fractography and interphases. Carbon 42, 515-529 (2004). https://doi.org/10.1016/j. carbon.2003.12.085

28. Bohse, J.: Acoustic emission characteristics of micro-failure processes in polymer blends and composites. Compos. Sci. Technol. 60, 1213-1226 (2000). https://doi.org/10.1016/s02663538(00)00060-9

29. Li, L., Lomov, S.V., Yan, X., Carvelli, V.: Cluster analysis of acoustic emission signals for 2D and 3D woven glass/epoxy composites. Compos. Struct. 116, 286-299 (2014). https://doi.org/10.1016/j. compstruct.2014.05.023
30. Li, L., Swolfs, Y., Straumit, I., Yan, X., Lomov, S.V.: Cluster analysis of acoustic emission signals for 2D and 3D woven carbon fiber/epoxy composites. J. Compos. Mater. 50, 1921-1935 (2016). https://doi.org/10.1177/0021998315597742

31. Gutkin, R., Green, C.J., Vangrattanachai, S., Pinho, S.T., Robinson, P., Curtis, P.T.: On acoustic emission for failure investigation in CFRP: pattern recognition and peak frequency analyses. Mech. Syst. Signal Process. 25, 1393-1407 (2011). https://doi.org/10. 1016/j.ymssp.2010.11.014

32. Uenoya, T., Fujii, T.: Thermoelastic characterization on damage progress in toughened resin carbon fiber fabric composite. Polym. Blends Polym. Compos. 137, 139-146 (1998)

33. Ramirez-Jimenez, C.R., Papadakis, N., Reynolds, N., Gan, T.H., Purnell, P., Pharaoh, M.: Identification of failure modes in glass/polypropylene composites by means of the primary frequency content of the acoustic emission event. Compos. Sci. Technol. 64, 1819-1827 (2004). https://doi.org/10.1016/j.compscitech. 2004.01.008

34. Hamstad, M.A., O'Gallagher, A., Gary, J.: Examination of the application of a wavelet transform to acoustic emission signals: Part 2. Source location. J. Acoust. Emiss. 20, 62-81 (2002)

35. Marec, A., Thomas, J.H., El Guerjouma, R.: Damage characterization of polymer-based composite materials: multivariable analysis and wavelet transform for clustering acoustic emission data. Mech. Syst. Signal Process. 22, 1441-1464 (2008). https://doi.org/10. 1016/j.ymssp.2007.11.029

36. Lorenzo, L., Hahn, H.T.: Damage assessment by acousto-ultrasonic technique in composites. In: Whitcomb, J.D. (ed.) Composite Materials Testing and Design. ASTM STP 972: 380-397 (1988)

37. Alif, N., Carlsson, L.A.: Failure mechanisms of woven carbon and glass composites. In: Armanios, E.A. (ed.) Composite Materials: Fatigue and Fracture (Sixth Volume). ASTM STP 1285: 471-493 (1997)

38. Fowler, T.J., Blessing, J.A., Conlisk, P.J., Swanson, T.L.: The Monpac system. J. Acoust. Emiss. 8, 1-10 (1989)

39. Tang, X.D., Whitcomb, J.D.: Progressive failure behaviors of $2 \mathrm{D}$ woven composites. J. Compos. Mater. 37, 1239-1259 (2003). https://doi.org/10.1177/002199803033468

40. Konsztowicz, K., Nowak, M., Baran, I., Ziąbka, M., Chlopek, J.: Detection of micro-crack initiation in epoxy matrix material with use of acoustic emission. In: Proceedings of ECCM17, Munich, Germany, 26-30th June, pap 3.01-07 (2016)

41. Quaresimin, M., Carraro, P.A., Maragoni, L.: Early stage damage in off-axis plies under fatigue loading. Compos. Sci. Technol. 128, 147-154 (2016). https://doi.org/10.1016/j.compscitech.2016. 03.015 